\title{
Raman and IR spectroscopy of manganese superoxide dismutase, a pathology biomarker
}

\author{
Catalina David ${ }^{\mathrm{a}, *}$, Cristiano d'Andrea $^{\mathrm{b}}$, Eloïse Lancelot $^{\mathrm{a}}$, Jörg Bochterle ${ }^{\mathrm{c}}$, Nicolas Guillot ${ }^{\mathrm{d}}$, \\ Barbara Fazio $^{\mathrm{b}}$, Onofrio M. Maragò ${ }^{\mathrm{b}}$, Angela Sutton ${ }^{\mathrm{e}}$, Nathalie Charnaux ${ }^{\mathrm{e}}$, Frank Neubrech $^{\mathrm{c}}$, \\ Annemarie Pucci ${ }^{c}$, Pietro G. Gucciardi ${ }^{b}$, Marc Lamy de la Chapelle ${ }^{\mathrm{d}}$ \\ a HORIBA Scientific 231 Rue de Lille, 59650 Villeneuve d'Ascq, France \\ b CNR IPCF Istituto per i Processi Chimico-Fisici, Viale F. Stagno D'Alcrontres 37, 98158 Messina, Italy \\ ${ }^{\mathrm{c}}$ Kirchhoff-Institut für Physik, Im Neuenheimer Feld 227, D-69120 Heidelberg, Germany \\ d Laboratoire CSPBAT, UMR 7244, UFR SMBH, Université Paris 13, 74 rue Marcel Cachin, 93017 Bobigny, France \\ e INSERM U698, Bioingénierie cardiovasculaire, Université Paris 13, rue Marcel Cachin, 93017, Bobigny, France
}

\section{A R T I C L E I N F O}

\section{Article history:}

Received 22 August 2011

Received in revised form 8 March 2012

Accepted 5 June 2012

Available online 3 July 2012

\section{Keywords:}

Biomarker

Raman spectroscopy

FTIR spectroscopy

Superoxide dismutase

Spectral fingerprint

\begin{abstract}
A B S T R A C T
The vibrational spectrum, Raman and infrared, of manganese superoxide dismutase (MnSOD), is presented.

Both Raman and Fourier-Transform (FT) IR spectra of the lyophilised powder of MnSOD strongly suggest that its secondary structure composition is dominated by $\alpha$-helix and $\beta$-sheet which is in good agreement with the crystallographic data. In order to obtain more results on the protein vibrational characterisation and to highlight the suitable experimental conditions a multiwavelength Raman detection was performed at 532, 632.8, 638, 660 and $785 \mathrm{~nm}$. Moreover, we studied the protein behaviour during the lyophilisation process in the presence of the phosphate buffer. Our results show significant differences in the protein conformation and stability during freeze drying of the buffered protein solution compared to the aqueous solution.
\end{abstract}

(c) 2012 Elsevier B.V. All rights reserved.

\section{Introduction}

Superoxide dismutase (SOD) is an oxidoreductase that catalyses the reaction between superoxide anions and hydrogen [1]. Human SOD presents three forms: SOD1 located in cytoplasm, SOD2 located in mitochondria and SOD3 located outside the cell [2]. The SOD1 is a dimer while the two others are tetramers. SOD1 and SOD3 contain copper and zinc, whereas SOD2 has manganese in its reactive centre. The human mitochondrial manganese superoxide dismutase (MnSOD) is a homotetramer [3-5] of $22 \mathrm{kDa}$ per subunit, each harbouring a $\mathrm{Mn}^{3+}$ ion. MnSOD is encoded by nuclear DNA and is inducible by reactive oxygen species (ROS), cytokines, and ethanol. MnSOD is synthesized with a mitochondrial targeting sequence, which drives its mitochondrial import [6].

In response to oxidative stress, the human body has developed an elaborate antioxidant system to detoxicate reactive oxygen species (ROS) in which MnSOD plays a major role. MnSOD is, in fact, the principal antioxidant capable of converting superoxide radicals to hydrogen peroxide and molecular oxygen within mitochondrial

\footnotetext{
* Corresponding author. Tel.: +33 03205918 00; fax: +33 0320591808 .

E-mail address: catalina.david@gmail.com (C. David).
}

matrix. MnSOD is essential for life as dramatically illustrated by the neonatal lethality of mice that are deficient in this protein [7-9]. Mices expressing only 50\% of the normal complement of MnSOD demonstrate increased susceptibility to oxidative stress and severe mitochondrial dysfunction resulting from elevation of reactive oxygen species. Furthermore, because of its important biological role, MnSOD is considered as a valuable biomarker for medical diagnosis. For instance, plasma MnSOD levels were found to be significantly higher in patients with ovarian carcinoma [10] and in patients with sepsis who died in comparison to survivors [11]. Moreover, cerebrospinal fluid samples from patients with malignant tumours revealed high levels of MnSOD protein, up to 45-fold greater than controls [12]. In medical applications, MnSOD is measured either by ELISA to assess MnSOD proteins levels or by enzymatic assay to assess its activity ensured by homotetramers. However, it is not possible to distinguish monomers and homotetramers in a biological sample by Enzyme-linked immunosorbent assay (ELISA). A genetic dimorphism leads to the incorporation of either an alanine or a valine in the mitochondrial targeting sequence of MnSOD and affects the secondary structure of the MnSOD precursor. Hence, an $\alpha$-helix is associated with alanine and a $\beta$-sheet is associated with valine. These amino acids modulate MnSOD mature protein levels and activity $[2,13]$. 
Knowing the status of the MnSOD activity is crucial to assess its role as a regulator in cell biology. The protein activity is closely related to its conformation and structure which represent critical information to understand the relationship between structure and function. Thus, identification of the protein through its conformational features would be essential in the medical applications.

Raman scattering and FTIR spectroscopy are powerful tools for non-ambiguous protein detection and non-invasive in situ investigation of structural changes [14-26] with potential applications in early diseases diagnosis [27-30]. The complementary use of the Raman and FTIR extends the application spectrum of each individual technique to the characterisation of the protein structure in diverse physicochemical environments. For example, chemical groups such as carbonyls and nitrils give strong IR absorption, while aromatic rings and instauration lead to intense Raman bands. In some cases FTIR presents some advantages over Raman spectroscopy. FTIR, for example, does not suffer from interference with fluorescence, whereas this emission can be so strong that the Raman scattered light is completely masked. Both FTIR and Raman provide important information on both the secondary and the tertiary structure of proteins $[31,32]$ as well as on the protein environment $[33,34]$. The protein secondary structure, in particular, can be probed via the analysis of amide I, II and III bands, as widely proved by both theoretical [35-38] and experimental studies [39-44].

The Raman and IR spectra of MnSOD, in particular, can provide crucial information about conformational modifications induced by external factors, e.g. interaction with metal ions, drugs, other proteins or peptides, as well as on the environment surrounding the protein (water or other buffer solutions). Following the structural changes of this biomarker in vitro should be a real challenge in cancer diagnosis.

A complete spectral characterisation of MnSOD is of great use in biological sensing applications. Advanced techniques based on Raman and IR spectroscopies, such as SERS (Surface Enhanced Raman Scattering) and SEIRA (Surfaced Enhanced Infrared Absorption) are nowadays widely used for ultrasensitive chemical analysis down to single-molecule detection [45-47] and its field of application has been expanded from chemical-biochemical analysis to biomedical applications [48-50].

At present, only incomplete knowledge on the vibrational spectral fingerprint of MnSOD is available; for example, it is impossible to find a complete spectral assignment of spectral features to the known structure of MnSOD in the literature.

The MnSOD structure is mainly composed of $\alpha$-helixes [51] (secondary structure type, see Fig. 1).

Structural studies have mainly focused, up to now, on its isolation, characterisation, and location, whereas studies on its conformation have been limited [9,52-58]. More specific studies using FTIR [51], X-ray crystallography [50,59,60], nuclear magnetic resonance (NMR) [61], circular dichroism (CD) [9,62] and Resonant Raman spectroscopy [63] have permitted to elucidate the activesite structure of MnSOD. However, in most cases, these methods often follow structural changes by labelling areas of interest with certain chemical groups or amino acids or even by the replacement some groups within the active site.

In this paper, we emphasize the advantages of Raman and IR spectroscopies, in terms of applications in the biology. To this aim, we present a complete vibrational analysis of MnSOD in both native and denaturated forms. We compare the protein conformation in different buffer environments and highlight the correlation between the spectral features and the protein structure. Moreover, multiwavelength excitation experiments have been performed in order to complete the spectral analysis on MnSOD.

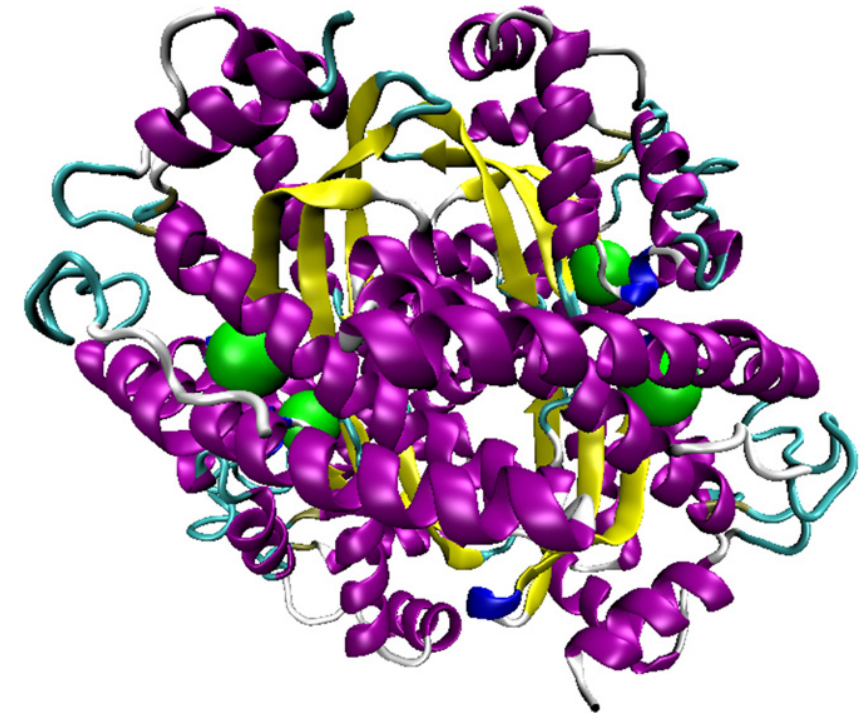

Fig. 1. The three dimensional structure of MnSOD tetramer (1ZTE pdb:ID from http://www.pdb.org): the four Mn atoms are represented in green. (For interpretation of the references to colour in this figure legend, the reader is referred to the web version of the article.)

\section{Materials and methods}

\subsection{Materials}

Recombinant manganese superoxide dismutase, from Escherichia coli (reference S8060-25N), was purchased from USBiological. The purity of the buffered protein solution, determined by SDS-PAGE was about $90 \%$. The protein $(\sim 0.5 \mathrm{mg} / \mathrm{ml})$ is supplied as a liquid in $50 \mathrm{mM}$ Tris $/ \mathrm{HCl}, \mathrm{pH} 7.7,0.15 \mathrm{M}$ sodium chloride, 5 mM DTT, 10\% glycerol.

\subsection{Sample preparation}

Samples have been prepared following two different protocols. First, the recombinant MnSOD was dialysed against $100 \mathrm{mM}$ PBS $\left(2 \mathrm{M}\right.$ of $\mathrm{Na}_{2} \mathrm{HPO}_{4}$ and $2 \mathrm{M}$ of $\mathrm{NaH}_{2} \mathrm{PO}_{4}$ ) buffer at $\mathrm{pH} 7.7$ and secondly against distilled water. After subjecting these samples to a freezedrying step, the two powders were recovered in different vessels and stored at $+4{ }^{\circ} \mathrm{C}$.

\subsection{Raman spectroscopy}

Raman spectroscopy experiments were performed on a LabRAM 300 Horiba Jobin-Yvon spectrometer with a $632.8 \mathrm{~nm}$ laser excitation (He-Ne laser). The Raman spectra were measured using an $80 \times$ magnification objective (NA=0.75) in back-scattering geometry, with a spectral dispersion of $3 \mathrm{~cm}^{-1} /$ pixel and a spatial resolution of about $1 \mu \mathrm{m}$. The position of the band maxima was reproducible within $\pm 1 \mathrm{~cm}^{-1}$. The laser power on the sample was $10 \mathrm{~mW}$.

Multiwavelength excitation experiments were performed using a XploRa Horiba Jobin-Yvon, spectrometer with several available excitation lines: $532 \mathrm{~nm}$ (spectral dispersion of $1.8 \mathrm{~cm}^{-1} /$ pixel), $638 \mathrm{~nm}$ (spectral dispersion of $1.1 \mathrm{~cm}^{-1} /$ pixel) and $785 \mathrm{~nm}$ (spectral dispersion of $1.3 \mathrm{~cm}^{-1}$ /pixel). A $100 \times$ magnification objective $(\mathrm{NA}=0.9)$ was used. The laser equivalent powers at sample were: $13.5 \mathrm{~mW}, 15 \mathrm{~mW}$ and $40 \mathrm{~mW}$ respectively. Further experiments were carried out with a LabRAM HR 800 Horiba Jobin-Yvon spectrometer with $660 \mathrm{~nm}$ excitation (spectral dispersion of $1.1 \mathrm{~cm}^{-1} /$ pixel) and a laser power of $11.7 \mathrm{~mW}$. 

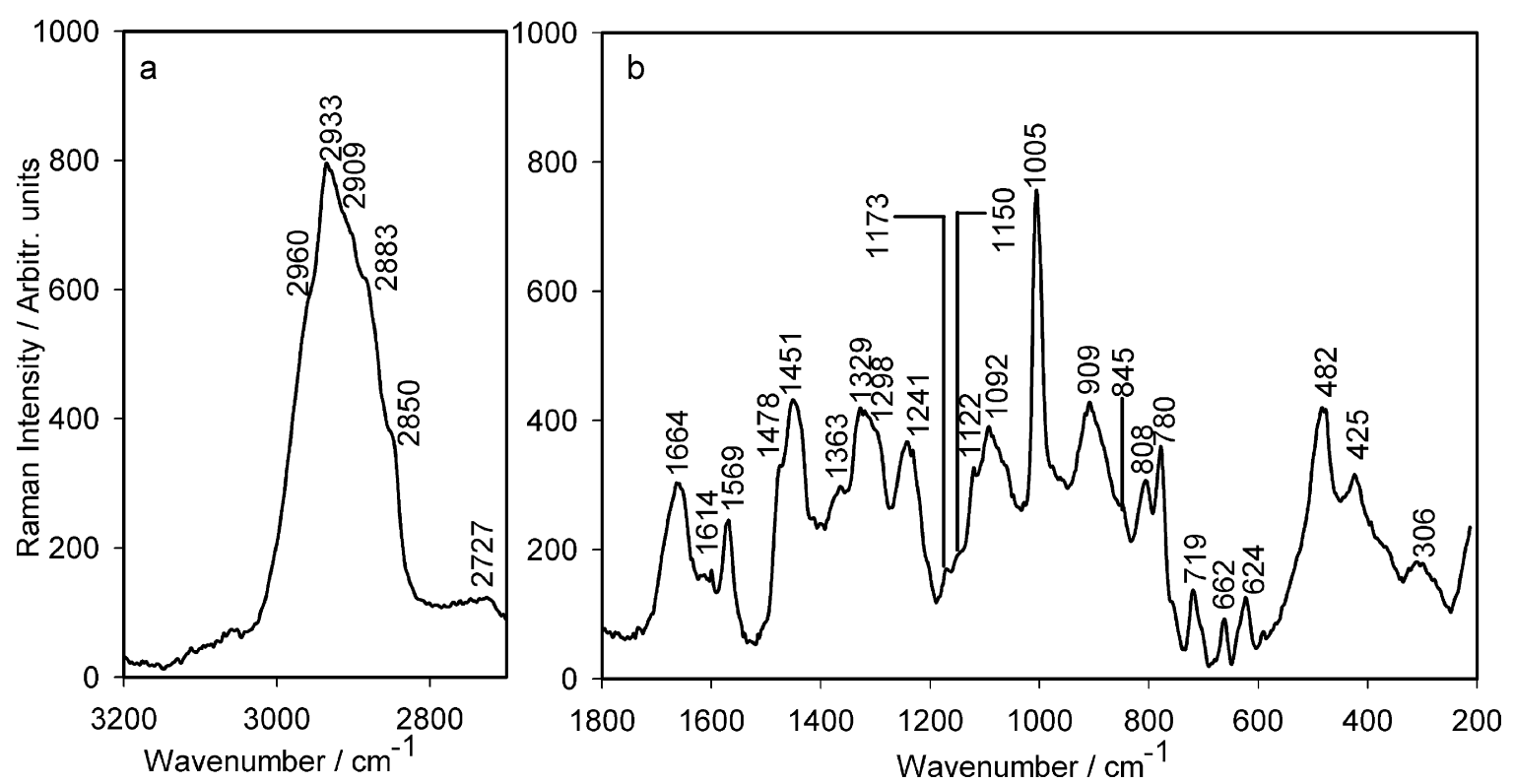

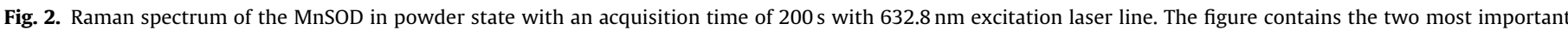
spectral regions for proteins.

\subsection{Infrared spectroscopy}

IR transmittance spectra were taken at normal incidence of light using an IR microscope (Bruker Hyperion 1000) coupled to a Fourier-Transform IR spectrometer (Bruker Tensor 27 with a LN2 cooled mercury-cadmium-telluride detector, optical path purged with dried air), which enables us to select single grains of micrometer-sized dimensions [64]. We have performed FT-IR measurements on powder grains and residuals of dried aqueous MnSOD protein solution drops cast on $\mathrm{CaF}_{2}$ substrates. With this method only very small amounts of molecules are necessary, different to the spectroscopy with IR cuvettes for aqueous solutions. It should be mentioned that dried molecules might have changed their conformation, which mainly affects IR spectra of the low-frequency modes. All measurements were performed in the spectral range between 1000 and $7000 \mathrm{~cm}^{-1}$ with a spectral resolution of $2 \mathrm{~cm}^{-1}$ and an aperture between $70 \mu \mathrm{m}$ and $25 \mu \mathrm{m}$ to exclusively focus on the protein grains and dried drops of MnSOD, respectively. As FTIR requires a reference spectrum to eliminate all background features arising from the optical beam path and the substrate, reference spectra are taken at least $250 \mu \mathrm{m}$ away from the proteins on the bare $\mathrm{CaF}_{2}$ substrate to exclude any influence of the proteins. Afterwards the spectrum of the proteins is normalized to the reference spectrum and the relative transmittance, featuring only the optical information of MnSOD proteins is obtained.

\section{Results and discussions}

\subsection{Raman vibrational fingerprint of $M n S O D$}

A representative Raman spectrum of MnSOD in lyophilised powder state in water environment is shown in Fig. 2. The most important spectral features are listed in Table 1 and we propose a tentative assignment of the vibrational Raman bands and their relation with the protein structure, based on a bibliographic study $[33,65,66,31,67-69]$ as well as on the X-ray crystallographic data $[51,59]$.

Amide I region. The amide I band of proteins, positioned between 1610 and $1700 \mathrm{~cm}^{-1}$ belongs primarily to the $\mathrm{C}=\mathrm{O}$ stretching mode and it is sensitive to the protein secondary structure. This arises due to the dependence of the inter-peptide vibration coupling and the arrangement of hydrogen bonds (involving the $\mathrm{C}=\mathrm{O}$ and $\mathrm{N}-\mathrm{H}$ groups) on the secondary structure $[33,65,66]$.

In the spectrum of MnSOD, the amide I band is located around $1660 \mathrm{~cm}^{-1}$. It is a strong and broad band containing several spectral contributions arising from different types of protein secondary structures.

Accessing this information requires a decomposition of the amide I band into the several components related to the different types of secondary structures. Several methods were proposed in the literature for the interpretation of the Raman spectra of proteins. Among them, we selected the method proposed by Przybycien et al. [31]. This allocation is based on a comparison between the X-ray structures of several tens of proteins and theirs IR and Raman spectra.

In Fig. 3(a) we present the amide I band fit. A sum of six Lorentzian functions was employed to fit the peak shape. The first three spectral components located at 1570, 1600 and $1614 \mathrm{~cm}^{-1}$ are the ring vibration bands due to the aromatic residues while the three other components effectively belong to the protein amide I band (see Table 2). The peak centred at $1652 \mathrm{~cm}^{-1}$ is usually assigned to the ordered $\alpha$-helix, the one at $1670 \mathrm{~cm}^{-1}$ to the $\beta$-sheet structure and the one at $1688 \mathrm{~cm}^{-1}$ to the vibrations of various turns (t) [31]. The origin of the spectral features near $1670 \mathrm{~cm}^{-1}$ is still unclear. Depending on the spectral assignment criteria, some research groups assign this contribution to the unordered $\alpha$-helix [24,31], besides the $\beta$-sheet structure. This type of non-regular structure may be considered as a $\beta$-strand feature or even some distorted $\alpha$-helix. From the different relative intensities of these bands given in Table 2, we assume that the protein structure contents high helical structures and fewer $\beta$-sheet structures. We could propose the following structure distribution: $\alpha$-helix between 55 and $65 \%, \beta$-sheet around $20 \%$ and various turns around $15 \%$. These results are in good agreement with the results of X-ray diffraction of MnSOD showing that the main type of secondary structure is the $\alpha$-helix type (48\%), while the $\beta$-sheet structure type represents $12 \%$ of the entire protein structure [51,59].

In our studies it is plausible that the lyophilisation process can induce some modifications of the protein structure, thus the 
Table 1

Assignment of the MnSOD Raman modes and correlation with the molecular structure.

\begin{tabular}{|c|c|c|}
\hline Frequency $\left(\mathrm{cm}^{-1}\right)$ & Vibrational assignment & Structural information \\
\hline $306,425,482$ & $\mathrm{Mn}-\mathrm{O}$ & Metal-ligand vibration \\
\hline 624 & Phe(ring stretching) & $\begin{array}{l}\text { Ratio with tyrosine at } 644 \mathrm{~cm}^{-1} \text { to } \\
\text { estimate Phe/Tyr }\end{array}$ \\
\hline 662 & $v(\mathrm{C}-\mathrm{S})$ & Met, Cys \\
\hline 719 & $\nu(\mathrm{C}-\mathrm{S})$ & Met, Cys \\
\hline 780 & $v(\mathrm{C}-\mathrm{C}=\mathrm{O})$ & \\
\hline \multicolumn{3}{|l|}{808} \\
\hline $837 / 848$ & $\begin{array}{l}\text { Tyr(ring stretching) Fermi } \\
\text { resonance between ring } \\
\text { fundamental and overtone }\end{array}$ & $\begin{array}{l}\text { Ratio } I_{848} / I_{837} \text { direct measure of the } \\
\text { negative charge state of the } \\
\text { phenolic oxygen and of the } \\
\text { tyrosine environment }\end{array}$ \\
\hline $909,917,930$ & Aliphatic $v(C-C)$ & $\begin{array}{l}\text { Conformational change markers } \\
\text { broaden and lose intensity with } \\
\text { denaturation }\end{array}$ \\
\hline 1005,1029 & Phe (ring stretching) & $\begin{array}{l}\text { Conformation-insensitive } \\
\text { frequency/intensity reference }\end{array}$ \\
\hline $1050,1060,1074,1092$ & Non aromatic $v(\mathrm{C}-\mathrm{N})$ and $v(\mathrm{C}-\mathrm{C})$ & $\begin{array}{l}\text { Conformational change markers } \\
\text { broaden and lose intensity with } \\
\text { denaturation }\end{array}$ \\
\hline 1122 & $\begin{array}{l}\text { Non aromatic } v(C-C) \operatorname{Trp} \text { (ring } \\
\text { stretching) }\end{array}$ & \\
\hline 1150, 11731203 & $\begin{array}{l}\text { Aliphatic side chain } \delta\left(\mathrm{CH}_{3}\right) \text { Trp } \\
\text { (ring stretching) }\end{array}$ & \\
\hline 1232 & - & \\
\hline 1241 & Amide III & Antiparallel $\beta$-sheet \\
\hline 1250 & Amide III & Random structure \\
\hline 1298 & Amide III & $\alpha$-Helix \\
\hline \multicolumn{3}{|l|}{$1311,1320,1329$} \\
\hline 1363,1378 & Non aromatic $\delta\left(\mathrm{CH}_{2}\right)$ & \\
\hline 1399,1411 & Trp (inodole ring) & $\begin{array}{l}\text { Ring environment. Sharp, intense } \\
\text { line for buried residues. Intensity } \\
\text { diminished on exposure or } \\
\text { environmental change. Band } \\
\text { contour of doublet near } 1360-1380 \\
\text { is sensitive to environment }\end{array}$ \\
\hline 1399,1411 & $v\left(\mathrm{COO}^{-}\right)$ & Protein state of ionisation \\
\hline 1451,1476 & Non aromatic $\delta\left(\mathrm{CH}_{2}\right)$ & \\
\hline 1506 & $\nu(\mathrm{N}-\mathrm{C})$ & \\
\hline 1570 & Trp (ring stretching) & \\
\hline 1600 & Phe (ring stretching) & \\
\hline 1614 & Tyr, Phe, Trp (ring stretching) & \\
\hline 1652 & Amide I & $\alpha$-Helix \\
\hline 1670 & Amide I & Antiparallel $\beta$-sheet \\
\hline 1688 & Amide I & Turns \\
\hline 2850 & $\mathrm{CH}_{2}$ symmetrical stretching & \\
\hline 2883 & $\mathrm{CH}_{2}$ antisymmetrical stretching & \\
\hline 2960 & $\mathrm{CH}$ asymmetrical stretching of $\mathrm{CH}_{3}$ & \\
\hline
\end{tabular}

presence of a small amount of unordered $\alpha$-helix should not be surprising. The Raman band at $1670 \mathrm{~cm}^{-1}$ may therefore contain both contributions from the antiparallel $\beta$-sheet and from the unordered $\alpha$-helix structure.

Amide III region. The spectral region between 1225 and $1300 \mathrm{~cm}^{-1}$ in the Raman spectra of proteins is called the amide III. It is well known that this band provides helpful information about the protein structure because it is sensitive to the geometry of the protein backbone. The amide III vibration is a combination of $\mathrm{C}-\mathrm{N}$ bond stretching and $\mathrm{N}-\mathrm{H}$ bond bending $[33,67,68]$ which reveals several spectral region related to the secondary structure of the protein: $1230-1235 \mathrm{~cm}^{-1}$ for $\beta$-sheet structure, $1240-1250 \mathrm{~cm}^{-1}$ for random coil conformation and $1260-1300 \mathrm{~cm}^{-1}$ for $\alpha$-helix conformation. In Fig. 3(b) the amide III band of MnSOD is shown. We can identify the shoulder of the spectral contribution of the $\alpha$-helix structures near $1298 \mathrm{~cm}^{-1}$. A smaller amount of $\beta$-sheet structure contribution is indicated near $1232 \mathrm{~cm}^{-1}$. According to the literature, we assign the contribution near $1241 \mathrm{~cm}^{-1}$ and $1250 \mathrm{~cm}^{-1}$ to the random-coil motifs (connecting loops) [14,34].

Table 2

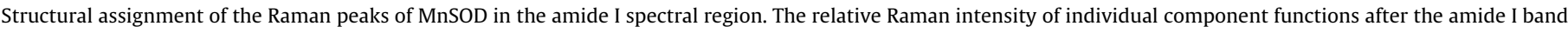
fit is given in the table.

\begin{tabular}{|c|c|c|}
\hline $\begin{array}{l}\text { Peak position }\left(\mathrm{cm}^{-1}\right) \\
\text { Amide I }\end{array}$ & $\begin{array}{l}\text { Relative Raman } \\
\text { Intensity (Arbr. units) }\end{array}$ & $\begin{array}{l}\text { Structural } \\
\text { Assignment [54] }\end{array}$ \\
\hline 1570 & 31,800 & Trp (ring stretching) \\
\hline 1600 & 570 & Phe (ring stretching) \\
\hline 1614 & 23,300 & Tyr, Phe, Trp (ring stretching) \\
\hline 1652 & 42,000 & $\alpha$-Helix \\
\hline 1670 & 22,850 & Antiparallel $\beta$-sheet or unordered $\alpha$-Helix \\
\hline 1688 & 10,400 & Turns \\
\hline
\end{tabular}



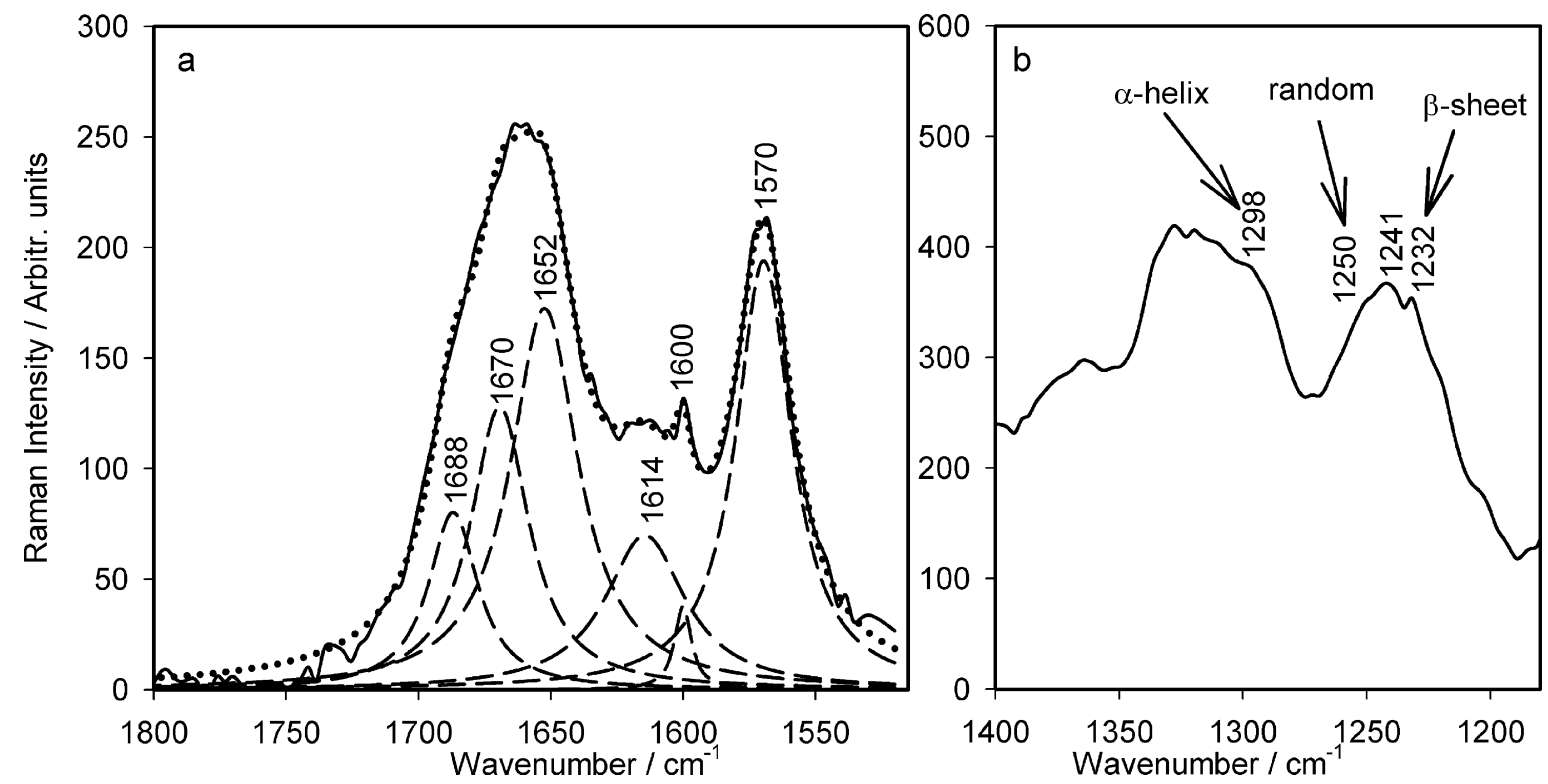

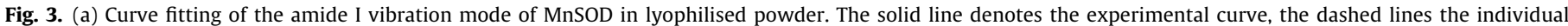

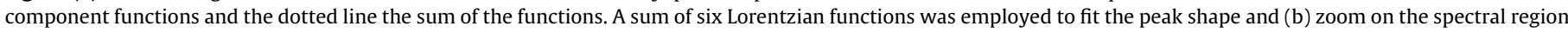
of protein amide III band.

The spectral position of the amide I $\left(1652 \mathrm{~cm}^{-1}\right)$ and amide III bands (1235-1298 $\mathrm{cm}^{-1}$ ), together with the considerations drawn on the secondary structure composition (Table 2), demonstrate the predominance of $\alpha$-helical structures in MnSOD. In addition, the analysis of the amide III band indicates the presence of the randomcoils structures. These results are in a good agreement with the crystallographic data concerning this protein [59].

Fermi doublet region. Raman spectroscopy brings valuable information about different aromatic amino acids and their sensitivity to the environment (see Table 1 ). Some of the vibrational bands of tyrosine (Tyr) or tryptophan (Trp) are sensitive to the environment [69]. In particular, intensity variations of the Fermi resonance doublet at 830 and $850 \mathrm{~cm}^{-1}$ or changes in the relative intensity ratio are associated to the extent of hydrogen bonding of the phenolic hydroxyl. Generally, when the protein is in a partially unfolded state the Tyr groups are located in a hydrophobic environment and act as proton donor for the formation of strong hydrogen bonds with a negative acceptor, e.g. $\mathrm{CO}_{2}{ }^{-}$. In this case the intensity ratio $\left(I_{850} / I_{830}\right)$ is 3:10 [69-71]. Conversely, an intensity ratio close to 10:4 indicates that the hydrogen bonding is weaker or that an acidic external proton is bonded to the phenolic oxygen.

MnSOD contains eight tyrosine residues per monomer and the Fermi doublet is located at 837 and $848 \mathrm{~cm}^{-1}$ (see Fig. 4). The intensity ratio of the two peaks is close to 10:7 and strongly indicates that most Tyr groups are exposed to a polar environment and form weak hydrogen bonds. This conclusion may suggest that, in this study, the lyophilisation process did not induce a global protein unfolding, since in the native protein conformation tyrosine residues are quite exposed to the solvent.

\subsection{IR vibrational fingerprint of MnSOD}

In Fig. 5, we present a typical relative transmission spectrum (average over 1000 scans) of a MnSOD powder grain on a $\mathrm{CaF}_{2}$ substrate. The grain was much bigger than the circular aperture (diameter $70 \mu \mathrm{m}$ ), so we had to focus on a thin area at the edge of the grain to get a good transmission signal. For comparison we dissolved the protein in water and put a $2 \mu \mathrm{l}$ drop of the solution on a $\mathrm{CaF}_{2}$ substrate as well. After evaporation of the water in ambient conditions the $1.5 \mathrm{~mm}$ stain left by the drop shows in the optical microscope a dense outer ring and many loosely distributed clusters of dense material inside (diameters up to $50 \mu \mathrm{m}$ ). A typical spectrum (average over 100 scans) taken two days after evaporation is also shown in Fig. 5. Depending on the lateral measurement position the spectra show slightly different frequencies and of course larger differences in transmission due to the different sizes of the protein clusters and grains.

Some clusters' spectra taken directly after evaporation and spectra from the outer ring show similar, but smeared out, spectral features and have a broader $\mathrm{O}-\mathrm{H}$ peak at around $3282 \mathrm{~cm}^{-1}$. We attribute this to the presence of residual water. These spectra are thus neglected in the evaluation. Spectra not showing water, but taken directly after evaporation, do not differ from the spectra taken two days later.

Fig. 6(a) shows a zoom on the fingerprint region of the protein spectrum. To facilitate comparability, all spectra are normalized to the size of the amide I peak. The thin lines show different spatial measurements positions, to illustrate the deviations within the stain of the dried drop (including spectrum (b) from Fig. 5), while the bold line is the normalized spectrum of the grain (also in Fig. 5(a)). In this representation, besides minor differences (e.g. shape of amide I and III) both types of IR spectra are in rather good

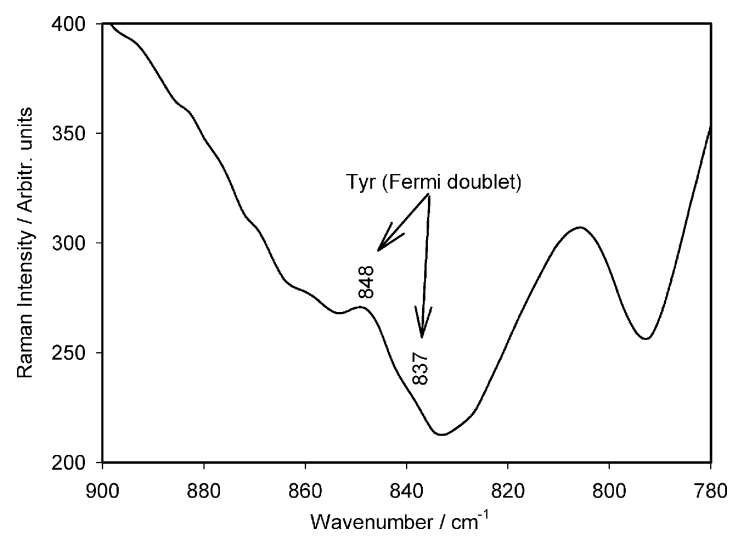

Fig. 4. Vibrational bands of Fermi resonance doublet of tyrosine in MnSOD Raman spectrum. 


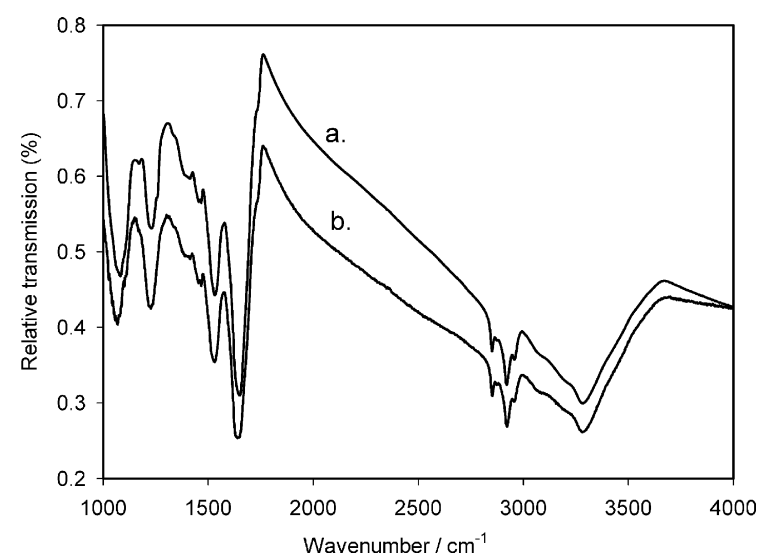

Fig. 5. Typical IR spectrum of MnSOD in lyophilised powder state (a) and of the residuals of a dried solution drop and (b). The spectra were taken with a resolution of $2 \mathrm{~cm}^{-1}$ and an aperture of $70 \mu \mathrm{m}$ and $25 \mu \mathrm{m}$ respectively. The amide bands are assigned according to reference 33 .

coincidence which leads to the conclusion that solvating and drying the protein does not strongly change the amide bonds of the molecule and thus the secondary structure is almost conserved.

In the spectral region between $1770 \mathrm{~cm}^{-1}$ and $2800 \mathrm{~cm}^{-1}$ the protein has no vibrational bands and one would expect a transmission close to $100 \%$. Here, this is clearly not the case with spectra from different clusters showing different slopes. This background can be explained by resonant Mie scattering of the differently shaped clusters in the dried drop [72] and can decrease the frequency of the amide I band of up to $20 \mathrm{~cm}^{-1}$ [73]. Since for this publication, we are not so interested in the actual peak intensities, we decided to evaluate our spectra without the correction algorithm given in reference 43 and instead use the second derivative to gain more insight into the spectral components and to get rid of the broadband Mie signal.

The 2nd derivatives of the not normalized spectra (Savitzky Golay filter, 2nd order polynomial, 25 or 13 smoothing points) are shown in Fig. 6(b). To reduce the noise of the spectra from the dried drop (thin lines), the derivative was obtained by using 25 smoothing points, while the given peak positions are derived from the spectrum of the grain (bold line) using only 13 smoothing points. This is done to minimize artificial shifts caused by the smoothing algorithm. Upward pointing peaks indicate the position of the highest curvature in the relative transmission spectrum and thus the position of the peak or shoulder.

The amide I band $\left(1610-1700 \mathrm{~cm}^{-1}\right)$ has its major contribution at $1657 \mathrm{~cm}^{-1}$, which is specific for helical protein structure. The shoulder at $1627 \mathrm{~cm}^{-1}$ is in the typical region for $\beta$-sheet vibrations [74]. An artificially created peak cut off due to zero transmission in this region is possible in general, but unlikely because we see a similar shape for all spectra, even for those taken from very thin clusters. The signature of antiparallel $\beta$-sheets is expected to be around $1695 \mathrm{~cm}^{-1}$ [32]. The band intensities underline the high helical contents in the MnSOD structure. The amide II band, which is only weakly excited in Raman spectroscopy, has components at $1515 \mathrm{~cm}^{-1}, 1530 \mathrm{~cm}^{-1}$ and $1545 \mathrm{~cm}^{-1}$ which are in overlapping regions of Tyrosin side chain, random, $\beta$-sheet and $\alpha$-helical motives [32]. The IR amide III band $\left(1200-1340 \mathrm{~cm}^{-1}\right)[32,33]$ is much less intense and in most cases it is not sensitive to the environment. Our experimental data show a broad absorption, consisting of peaks centred at 1217 and $1239 \mathrm{~cm}^{-1}$. The first one can be attributed to histidine anion (HIS ${ }^{-}$) and the latter to $\beta$-sheet and random contribution. The shoulder at $1261 \mathrm{~cm}^{-1}$ is only present in the spectrum of the lyophilised grain and in one spectrum of a big cluster of the dried drop. We doubt that this originates from helical content [74], because all other spectra of the dried drop do not show this feature. This change is also not correlated to any change in the signal of helical content in the amide I region. Due to its narrow bandwidth we believe that this signal does not originate from the protein, but from some kind of contamination which is lost, when the protein is completely solvated and dried afterwards. This might have been not the case for the one big cluster where we still observed this signal.

In comparison to Raman studies we observe additional vibrational bands (corresponding to weakly active Raman modes) which are not assigned to structured features but originate from the various side chains [32]. The strongest ones are: 1082, 1413, 1455 and $1467 \mathrm{~cm}^{-1}$. The bands centred at $1467 \mathrm{~cm}^{-1}$ and $1455 \mathrm{~cm}^{-1}$ belong to protein side chain deformation vibrations $\left(\delta\left(\mathrm{CH}_{3}\right)\right.$ and $\delta\left(\mathrm{CH}_{2}\right)$ respectively), while the band centred at $1413 \mathrm{~cm}^{-1}$ supplies information about the ionisation state $\left(v\left(\mathrm{COO}^{-}\right)\right)[75]$. The strong band at $1082 \mathrm{~cm}^{-1}$ can be attributed to $\mathrm{C}-\mathrm{C}$ and $\mathrm{C}-\mathrm{O}$ vibrations which e.g. are very pronounced in saccarides [76].

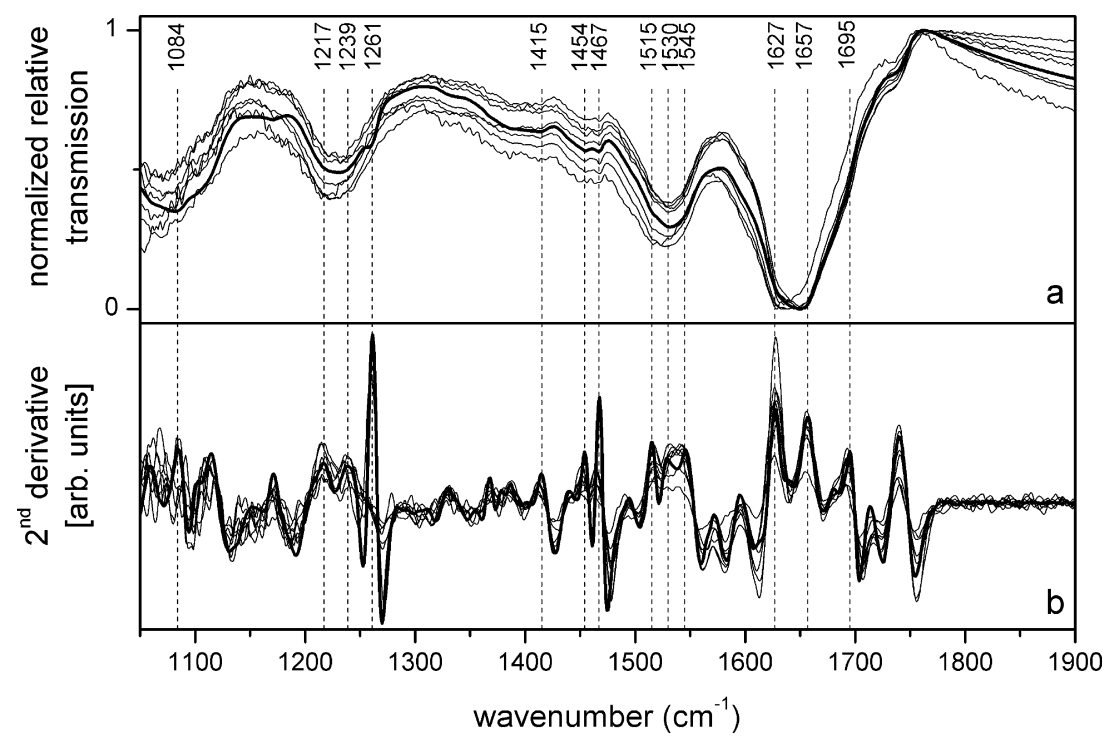

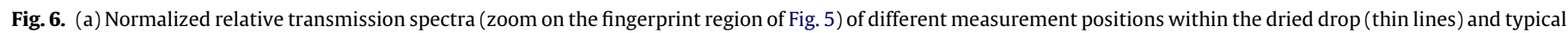
measurement of a protein grain (bold line) and (b) 2nd derivative of the spectra. The frequencies are derived from the maxima of the bold curve (grain spectrum). 

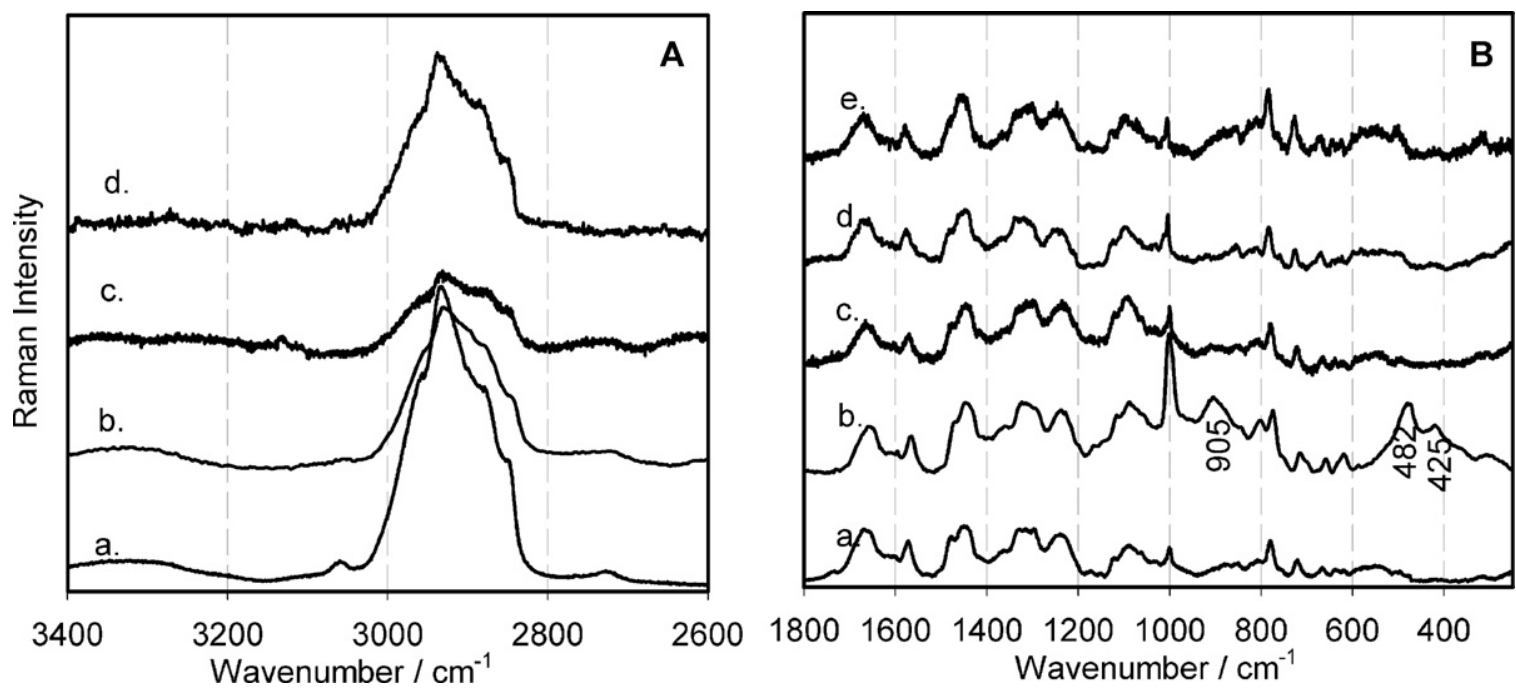

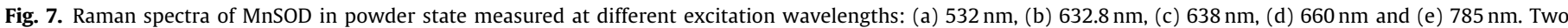
important spectral regions are shown on the figure: (A) the protein side chain deformation and (B) the protein fingerprint.

Due to the absorption of the $\mathrm{CaF}_{2}$ substrate, the measurements are restricted to the spectral region above $1000 \mathrm{~cm}^{-1}$.

The broad absorption band centred at $3282 \mathrm{~cm}^{-1}$ originates from the absorption of hydrating $\mathrm{H}_{2} \mathrm{O}(\mathrm{OH}$-stretching) and strongly suggests the presence of interstitial water molecules even after the lyophilisation step. $\mathrm{CH}$-stretching vibrational bands are located in the $2850-2960 \mathrm{~cm}^{-1}$ spectral range. As in Raman spectroscopy, these bands are very complex and they are only of limited use for the extraction of protein structural information.

Comparing our results from Raman and IR studies, we find good agreement with respect to the assignment of the bands.

\subsection{Raman multiwavelength excitation}

In order to establish the best instrumental conditions (excitation wavelengths and powers) to carry out vibrational spectra and test the sensitivity of standard Raman technique in the case of MnSOD, we have performed Raman experiments with multiwavelength excitation (RMW).

In our measurements, the available excitation wavelengths were: $532 \mathrm{~nm}, 632.8 \mathrm{~nm}, 638 \mathrm{~nm}, 660 \mathrm{~nm}$ and $785 \mathrm{~nm}$. The related
Raman spectra of the MnSOD in powder state are presented in Fig. 7. Due to the low sensitivity of the CCD detector at wavelengths $1 \mu \mathrm{m}$, the protein spectrum measured in the $\mathrm{C}-\mathrm{H}$ stretching region for $785 \mathrm{~nm}$ excitation results too weak to draw any conclusion and is not shown in Fig. 7(B).

Comparing the Raman spectra of the MnSOD measured at different wavelengths in the spectral range between $200-1800 \mathrm{~cm}^{-1}$ (Fig. 7(A)), we can note that all spectra are similar except that one for $632.8 \mathrm{~nm}$ excitation line. New bands are found at 425, 482 and $905 \mathrm{~cm}^{-1}$. The first two bands are related to the vibration of the metal-ligand in the protein while the band located at $905 \mathrm{~cm}^{-1}$ is assigned to the $\mathrm{C}-\mathrm{C}$ vibration in the polypeptide chain of protein. This evident dissimilarity in the case of $632.8 \mathrm{~nm}$ excitation line is probably due to the sample anisotropy when measuring spectra of different region.

This gives evidence that no significant signal increases can be pointed out from one specific excitation wavelength. Thus, there is not a resonance effect with the MnSOD protein. This result is of real importance since it means that there is no specific condition for the MnSOD studies. They are not limited to specific wavelengths and can be excited on a wide spectral range without any signal decrease.
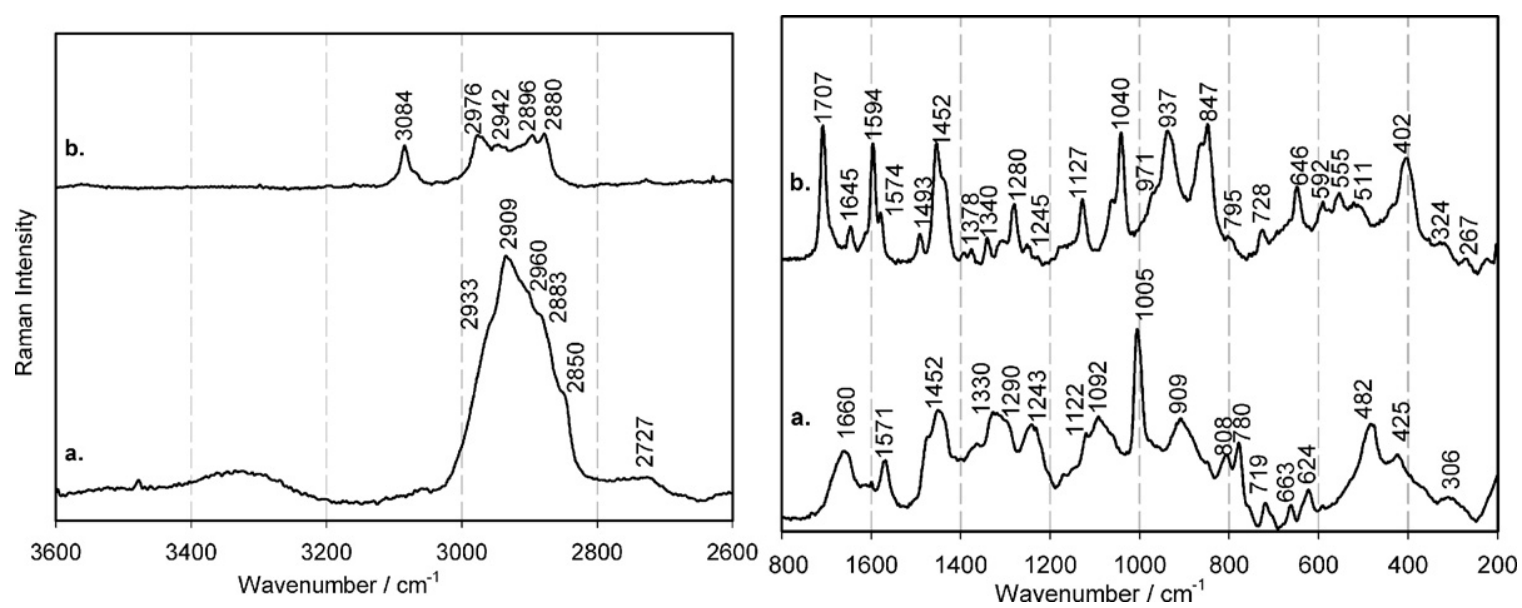

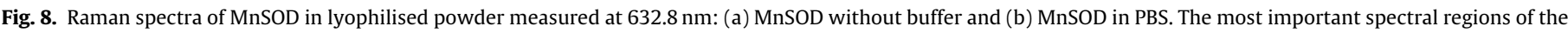
protein are shown on the figure: $2600-3600 \mathrm{~cm}^{-1}$ (left) and $200-1800 \mathrm{~cm}^{-1}$ respectively (right). 

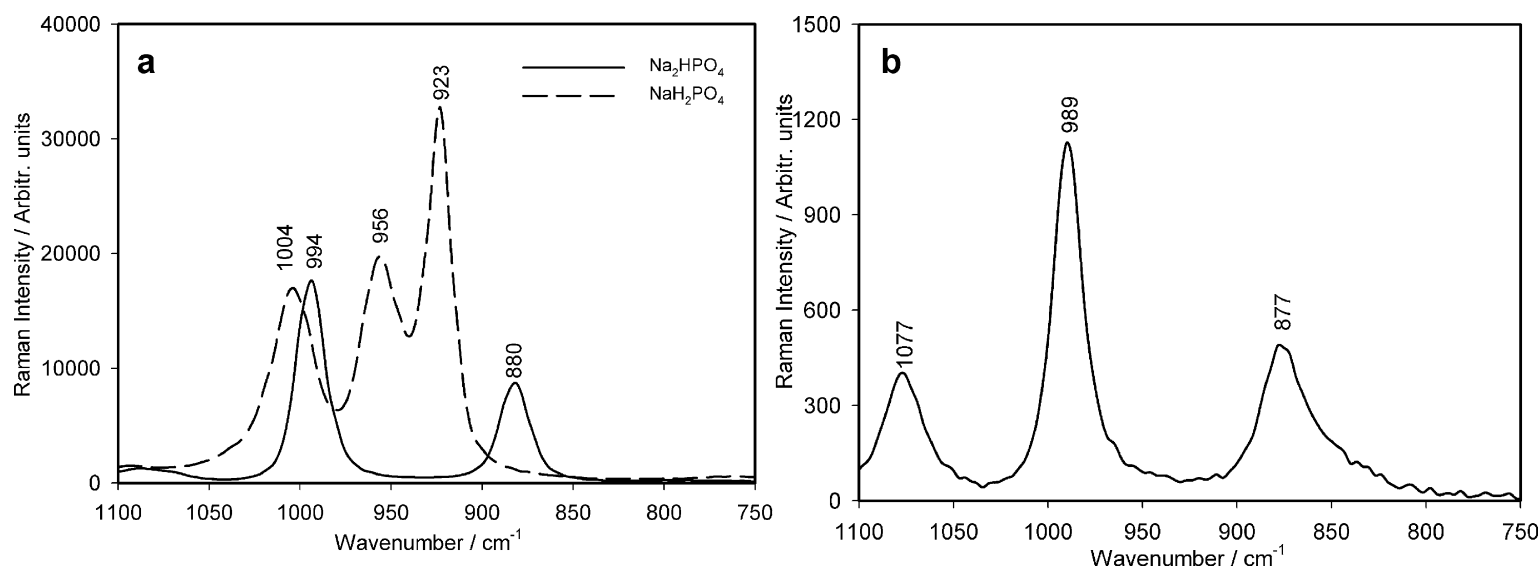

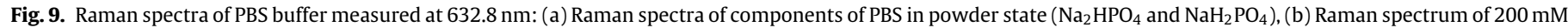
aqueous solution of PBS buffer at $\mathrm{pH}$ 7.4.

\subsection{The effect of the environment}

Due to their instability, proteins are typically handled in buffer solutions, special environments that ensure their conformation and biological activity.

In the present study, we measured the spectrum of MnSOD in presence of PBS buffer, besides pure water, in order to probe its structural stability in different environments during the lyophilisation process. The process of lyophilisation consists of freezing and then drying the protein. It is already known that following even a correct lyophilisation protocol can affect the protein structure $[77,78]$. Selection of the most suitable buffer for each protein is often dictated by physicochemical requirements of the active principle. Phosphate buffers upon starting of the freezing process, have a tendency to crystallise out of solution, resulting in major $\mathrm{pH}$ shifts during freezing, which in turn can lead to change in the tertiary structure and significant loss of activity of the protein [79].

Fig. 8 shows the Raman spectra of MnSOD lyophilised powder in presence (b) of $100 \mathrm{mM}$ phosphate buffer (PBS), pH 7.4, compared to MnSOD without buffer (a).

Indeed the two spectra are very different, indicating that the lyophilisation of the protein in PBS buffer affects the tertiary and even the secondary structure. In the spectrum (b), in fact, we note the absence of the $\alpha$-helix contribution in the amide I band $\left(1660 \mathrm{~cm}^{-1}\right)$ and the appearance of a small band located at $1645 \mathrm{~cm}^{-1}$ which is usually assigned to the unordered structure [43]. If we take a closer look at the amide III band, we detect a visible spectral shift of the $\alpha$-helix contribution from $1290 \mathrm{~cm}^{-1}$ (Fig. 8(a)) to $1280 \mathrm{~cm}^{-1}$ (Fig. 8(b)). This spectral shift may suggest that during the lyophilisation in presence of PBS the MnSOD loses, although not entirely, its ordered $\alpha$-helical content.

The Raman bands located at 847, 937 and $1040 \mathrm{~cm}^{-1}$ (Fig. 8(b)) belong to the vibration of the PBS components vibration in powder state and their positions are strongly affected by the $\mathrm{pH}$ changes during the lyophilisation (compare to Fig. 8) [80]. The Raman spectrum of PBS in aqueous solution is different compared to the powder one (Fig. 9(a) and (b) respectively). This difference is due to strong interactions between the components in solution. Moreover, the positions of the PBS bands are different to those of separate components. Actually, this is not surprising since the interaction between two components before or during lyophilisation is still very strong.

Analysing Fig. 8, we note that the PBS Raman bands overlap the proteins vibrational modes in the $750-1100 \mathrm{~cm}^{-1}$ spectral region. A possible major $\mathrm{pH}$ shift during freezing can be deduced from our spectrum (Fig. 8(b)). For example, the very low pH is observed on the onset of the Raman band at $1707 \mathrm{~cm}^{-1}$ which is attributed to the presence of an important amount of $\mathrm{C}=\mathrm{O}$ stretch of a protonated carboxylated group stretching of the aliphatic amino acids like Asp or Glu. These results show that the lyophilisation process of MnSOD in PBS is accompanied by major structural changes, namely the formation of disordered structures, and previously buried hydrophobic residues are exposed. Another proof of the protein denaturation during the lyophilisation in PBS is the remarkable presence of strong Raman bands of aromatics amino acids (Fig. 8(b)), since when folding the protein structure they are rather enveloped in a hydrophobic pocket $[69,70,81]$.

Contrarily, the lyophilisation of the protein aqueous solution may affect the tertiary structure but the most of the secondary structure motifs are preserved.

\section{Conclusions}

In this paper, we have presented the first combined IR and Raman broad-band vibrational study of MnSOD, a pathological biomarker. Since usually these vibrational techniques require important concentration of protein solution, we highlight in this study that the protein powder can be also employed to investigate the protein conformation. The detailed spectral analysis of the amide I Raman band shows that the native secondary structure of human MnSOD in solid state exhibits a predominance of $\alpha$-helixes. The established spectral features related to the protein secondary structures are in good agreement with the X-ray crystallographic data. Analysing the amide III band provided important information that supported the interpretation of the amide I band. IR measurements confirm the Raman spectral assignment, especially in the amide I band region. The combined Raman and FTIR spectroscopy is a valuable non-destructive method to probe MnSOD conformation. Since the conformation structure is the critical determinant of protein functionality, we investigated the protein lyophilisation process in the presence of PBS buffer. We confirm that in this case that the protein conformation is affected. Thus the tertiary and the secondary structures are strongly perturbed.

Having a complete Raman and FTIR vibrational characterisation of MnSOD is of real use. Indeed, it can be used as a spectral reference for any other analysis of the MnSOD either for structural studies (conformation and its eventual modifications) or for sensing techniques. In this latter case, it is necessary to determine the spectral signature of the MnSOD to be able to detect it in a specific environment (using SERS or SEIRA techniques for example) and then to use it for medical diagnosis [82]. This paper is then the first one, which gives the complete vibrational spectral signature of the 
MnSOD biomarker. This signature can be used for the development of specific and sensitive tools for the MnSOD detection and quantification in body fluids (plasma, buccal salivary samples, urine, etc) of patients.

On the other hand, our Raman multiwavelength measurements demonstrate that MnSOD Raman detection can be done on a fairly wide spectral range. This fact becomes even more interesting for SERS applications. Indeed, it is well-known that the maximum enhancement of Raman signal depends also on the position of the localised surface plasmon resonance (LSPR), which in turn depends on the laser excitation wavelength [83]. Thus, it is necessary in such experiments to tune the LSPR position to some proper laser excitation corresponding to the resonance wavelength and any kind of SERS substrate can be used to study or detect MnSOD protein.

\section{Acknowledgment}

This work has been supported by FP7-HEALTH-F5-2009241818-NANOANTENNA European project.

\section{References}

[1] L.A. MacMillan-Crow, D.L. Cruthirds, Free Radic. Res. 34 (2001) 325-336

[2] B. Halliwell, J.M.C. Gutteridge, Free Radicals in Biology and Medicine, The Clarendon Press, Oxford University Press, New York, NY, 1985, p. 10016.

[3] M.M. Werber, L.A. Greenstein, Free Radic. Res. Commun. 12-13 (1991)335-348.

[4] G.E.O. Borgstahl, H.E. Parge, M.J. Hickey, M.J. Johnson, M. Boissinot, R.A. Hallewell, J.R. Lepock, D.E. Cabelli, J.A. Tainer, Biochemistry 35 (1996) 4287-4297.

[5] W.C. Stallings, A.L. Metzger, K.A. Pattridge, J.A. Fee, M.L. Ludwig, Free Radic. Res. Commun. 12-13 (1991) 259-268.

[6] A.A. Sutton, A. Imbert, A. Igoudjil, V. Descatoire, S. Cazanave, D. Pessayre, F. Degoul, Pharmacogenet. Genom. 15 (2005) 311-319.

[7] J-C. Copin, Y. Gasche, P.H. Chan, Free Radic. Biol. Med. 28 (2000) 1571-1576.

[8] T. Ikegami, Y. Suzuki, T. Shimizu, K. Isono, H. Koseki, T. Shirasawa, Biochem. Biophys. Res. Commun. 296 (2002) 729-736.

[9] T.A. Jackson, T.C. Brunold, Acc. Chem. Res. 37 (2004) 461-470.

[10] A. Burak Dalan, A. Ergen, H. Yilmaz, A. Karateke, T. Isbir, J. Obstet. Gynaecol. Res. 34 (2008) 878-884.

[11] T. Brenner, S. Hofer, C. Rosenhagen, J. Steppan, C. Lichtenstern, J. Weitz, T. Bruckner, I.K. Lukic, E. Martin, A. Bierhaus, U. Hoffmann, M.A. Weigand, J. Surg. Res. 164 (2010) 163-171.

[12] C.S. Cobbs, D.S. Levi, K. Aldape, M.A. Israel, Cancer Res. 56 (1996) 3192-3195.

[13] A. Sutton, H. Khoury, C. Prip-Buus, C. Cepanec, D. Pessayre, F. Degoul, Pharmacogenetics 13 (2003) 145-157.

[14] S.-M. Choi, C.-Y. Ma, Food Chem. 102 (2007) 150-160.

[15] E.A. Quinn, R.T. Forbes, A.C. Williams, M.J. Oliver, L. McKenzie, T.S. Purewal, Int. J. Pharm. 186 (1999) 31-41.

[16] H. Ishizaki, P. Balaram, R. Nagaraj, Y.V. Venkatachalapathi, A.T. Tu, Biophys. J. 36 (1981) 509-517.

[17] M.R. Towler, A. Wren, N. Rushe, J. Saunders, N.M. Cummins, P.M. Jakeman, J. Mater. Sci.: Mater. Med. 18 (2007) 759-763.

[18] R. Williams, B. Gaber, J. Biol. Chem. 257 (1982) 13321-13323.

[19] M.C. Chen, R.C. Lord, J. Am. Chem. Soc. 98 (1976) 990-992.

[20] S.A. Overman, G.J. Thomas Jr., Biochemistry 37 (1998) 5654-5665.

[21] H. Susi, D.M. Byler, Appl. Spectrosc. 42 (1988) 819-826.

[22] V. Tattini Jr., D.F. Parra, B. Polakiewicz, R.N.M. Pitombo, Int. J. Pharm. 304 (2005) 124-134.

[23] M. Liang, V.Y.T. Chen, H.-L. Chen, W. Chen, Talanta 69 (2006) 1269-1277.

[24] N.C. Maiti, M.M. Apetri, M.G. Zagorski, P.R. Carey, V.E. Anderson, J. Am. Chem. Soc. 126 (2004) 2399-2408.

[25] C. David, S. Foley, C. Mavon, M. Enescu, Biopolymers 89 (2008) 623-634.

[26] C. David, S. Foley, M. Enescu, Phys. Chem. Chem. Phys. 11 (2009) 1-11.

[27] P. Chen, A. Shen, W. Zhao, S. Baek, H. Yuan, J. Hu, Appl. Opt. 48 (2009) 4743-4748.

[28] L.P. Choo-Smith, H.G. Edwards, H.P. Endtz, J.M. Kros, F. Heule, H. Barr, J.S. Robinson Jr., H.A. Bruining, G.J. Puppels, Biopolymers 67 (2002) 1-9.

[29] M. Gniadecka, H.C. Wulf, N. Nymark Mortensen, O. Faurskov Nielsen, D.H. Christensen, J. Raman Spectrosc. 28 (1997) 125-129.

[30] M.J. Romeo, S. Boydston-White, C. Matthaeus, M. Miljkovic, B. Bird, T. Chernenko, P. Lasch, M. Diem, in: M. Diem, P.R. Griffiths, J.M. Chalmers (Eds.), Vibrational Spectroscopy for Medical Diagnosis, Wiley, Indianapolis, IN, 2008, pp. 27-76.

[31] S.U. Sane, S.M. Cramer, T.M. Przybycien, Anal. Biochem. 269 (1999) 255-272.
[32] G. Vedantham, H.G. Sparks, S.U. Sane, S. Tzannis, T.M. Przybycien, Anal Biochem. 285 (2000) 33-49.

[33] R. Schweitzer-Stenner, Vib. Spectrosc. 42 (2006) 98-117.

[34] E.C.Y. Li-Chan, Trends Food Sci. Technol. 71 (1996) 361-370.

[35] J. Bandekar, Biochim. Biophys. Acta 1120 (1992) 123-143.

[36] T. Miyazava, E.R. Blout, J. Chem. Soc. 83 (1960) 712-719.

[37] V.M. Naik, S. Krimm, J. Int, Pep. Prot. Res. 23 (1984) 1-24.

[38] S.K. Gregurick, E. Fredj, R. Elber, R.B. Gerber, J. Phys. Chem. 101 (1997) 8595-8606.

[39] S.Y. Venyaminov, N.N. Kalnin, Biopolymers 30 (1990) 1259-1271.

[40] H. Susi, D.M. Byler, Biochem. Biophys. Res. Commun. 115 (1983) 391-397.

[41] S. Krimm, J. Bandekar, Adv. Prot. Chem. 38 (1986) 181-364.

[42] J.L. Arrondo, F.M. Goni, Prog. Biophys. Mol. Biol. 72 (1999) 367-405

[43] M. Jackson, H.H. Mantsch, Can. J. Chem. 69 (1991) 1639-1642.

[44] W.K. Surewicz, H.H. Mantsch, D. Chapman, Biochemistry 32 (1993) 389-394.

[45] E.J. Blackie, E.C. Le Ru, M. Meyer, M. Timmer, B. Burkett, P. Northcote, P.G. Etchegoin, Phys. Chem. Chem. Phys. 10 (2008) 4147-4153.

[46] E.J. Blackie, E.C. Le Ru, P.G. Etchegoin, J. Am. Chem. Soc. 131 (2009) $14466-14472$.

[47] E. Messina, E. Cavallaro, A. Cacciola, R. Saija, F. Borghese, P. Denti, B. Fazio, C. D'Andrea, P.G. Gucciardi, M.A. Iati, M. Meneghetti, G. Compagnini, V. Amendola, O.M. Marago, J. Phys. Chem. C 115 (2011) 5115-5122.

[48] P.D. Lacharmoise, E.C. Le Ru, P.G. Etchegoin, ACS Nano 3 (2008) 66-72.

[49] M. Iosin, F. Toderas, P.L. Baldeck, S. Astilean, J. Mol. Struct. 924-926 (2009) 196-200.

[50] S.D. Hudson, G. Chumanov, Anal. Bioanal. Chem. 394 (2009) 679-686.

[51] W.B. Greenleaf, J.J.P. Perry, A.S. Hearn, D.E. Cabelli, J.R. Lepock, M.E. Stroupe, J.A. Tainer, H.S. Nick, D.N. Silverman, Biochemistry 43 (22) (2004) 7038-7045.

[52] A. Mancini, A. Borrelli, A. Schiattarella, L. Aloj, M. Aurilio, F. Morelli, A. Pica A. Occhiello, R. Lorizio, R. Mancini, A. Sica, L. Mazzarella, F. Sica, P. Grieco, E. Novellino, D. Pagnozzi, P. Pucci, J. Rommelaere, Int. J. Cancer 123 (2008) 2684-2695.

[53] A.I. Katyshev, Yu.M. Konstantinov, V.F. Kobzev, Mol. Biol. 40 (2006) 327-329.

[54] X. Ren, C. Tu, D. Bhatt, J.J.P. Perry, J.A. Tainer, D.E. Cabelli, D.N. Silverman, J. Mol. Struct. 1-3 (2005) 168-173.

[55] Y. Abe, T. Okazaki, Arch. Biochem. Biophys. 253 (1987) 241-248.

[56] C.D. Pennington, E.M. Gregory, J. Bacteriol. 166 (1986) 528-532.

[57] P. Viglino, E.F. Orsega, E. Argese, R. Stevanato, A. Rigo, Eur. Biophys. J. 15 (1987) $225-230$.

[58] I. Ayala, J.J.P. Perry, J. Szczepanski, J.A. Tainer, M.T. Vala, H.S. Nick, D.N. Silverman, Biophys. J. 89 (2005) 4171-4179.

[59] U.G. Wagner, K.A. Pattridge, M.L. Ludwig, W.C. Stallings, M.M. Werber, C. Oefner, F. Frolow, J.L. Sussman, Prot. Sci. 2 (1993) 814-825.

[60] R.A. Edwards, H.M. Baker, M.M. Whittaker, J.W. Whittaker, G.B. Jameson, E.N Baker, J. Biol. Inorg. Chem. 3 (1998) 161-171.

[61] J.J. Villafranca, F.J. Yost Jr., I. Fridovich, J. Biol. Chem. 249 (1974) 3532-3536

[62] M.J. Bjerrum, Biochim. Biophys. Acta 915 (1987) 225-237.

[63] J. Maliekal, A. Karapetian, C. Vance, E. Yikilmaz, Q. Wu, T. Jackson, T.C. Brunold, T.G. Spiro, A.-F. Miller, J. Am. Chem. Soc. 124 (2002) 15064-15075.

[64] F. Neubrech, T.W. Cornelius, S. Karim, A. García-Etxarri, J. Aizpurua, A. Pucci, Phys. Rev. Lett. 101 (2008) 157403-157404.

[65] M. Cho, J. Phys. Chem. B 107 (2003) 9132-9138.

[66] V. Mikhonin, S.A. Asher, J. Phys. Chem. B 111 (2007) 4271-4279.

[67] M.C. Chen, R.C. Lord, J. Am. Chem. Soc. 96 (1974) 4750-4752.

[68] B.G. Frushour, J.L. Koeing, Biopolymers 13 (1974) 455-470.

[69] H. Van Dael, J.P. Lafaut, F. Van Cauwelaert, Eur. Biophys. J. 14 (1987) 409-414.

[70] M.N. Siamwiza, R.C. Lord, M.C. Chen, T. Takamatsu, I. Harada, H. Matsuura, T. Shimanouchi, Biochemistry 14 (1975) 4870-4876.

[71] N.T. Yu, E.J. East, J. Biol. Chem. 250 (1975) 2196-2202.

[72] P. Bassan, A. Kohler, H. Martens, J. Lee, H.J. Byrne, P. Dumas, E. Gazi, M. Brown, N. Clarke, P. Gardner, Analyst 135 (2010) 268-277.

[73] B. Bird, M. Miljkovic, M. Diem, J. Biophoton. 3 (2010) 597-608.

[74] E.A. Cooper, K. Knutson, in: J.N. Herron, W. Jiskoot, D.J.A. Crommelin (Eds.), Physical Methods to Characterize Pharmaceutical Proteins, Plenum, New York, 1997, pp. 101-143.

[75] F.R. Tortonda, J.L. Pascual-Ahuir, E. Silla, I. Tunon, F.J. Ramirez, J. Chem. Phys. 109 (1998) 592-602.

[76] J.J. Cael, J.L. Koenig, Infrared and Raman spectroscopy, Carbohydr. Res. 32 (1974) 79-91.

[77] S.O. Ugwu, S.P. Apte, Pharm. Technol. (2004) 86-113.

[78] W. Wang, Int. J. Pharm. 203 (2000) 1-60.

[79] K.A. Pikal-Cleland, J.F. Carpenter, J. Pharm. Sci. 90 (2001) 1255-1268.

[80] Y. Xie, Y. Jiang, D. Ben-Amotz, Anal. Biochem. 343 (2005) 223-230.

[81] A.L. Jenkins, R.A. Larsen, T.B. Williams, Spectrochim. Acta Part A 61 (2005) 1585-1594.

[82] C. David, N. Guillot, H. Shen, T. Toury, M. Lamy de la Chapelle, Nanotechnol. J. 21 (2010) 475501.

[83] N. Guillot, H. Shen, B. Fremaux, O. Péron, E. Rinnert, T. Toury, M. Lamy de la Chapelle, Appl. Phys. Lett. 97 (2010) 023113. 